\title{
Predictive value of lung function below the normal range and respiratory symptoms for progression of chronic obstructive pulmonary disease
}

\author{
M Albers, T Schermer, Y Heijdra, J Molema, R Akkermans, C van Weel
}

Radboud University Nijmegen Medical Centre, Nijmegen, The Netherlands

Correspondence to: M Albers, Radboud University Nijmegen Medical Centre, Department of Primary Care [117-HAG], PO Box 9101, 6500 HB Nijmegen, The Netherlands; m.albers@hag.umcn.nl

Received 30 June 2006 Accepted 12 August 2007 Published Online First 27 September 2007

\begin{abstract}
Background: Chronic obstructive pulmonary disease (COPD) is an insidiously starting disease. Early detection has high priority because of the possibility of early implementation of smoking cessation interventions. An evidence based model for case finding of COPD is not yet available.

Objective: To describe the early development of COPD, and to assess the predictive value of early signs (respiratory symptoms, lung function below the normal range, reversibility).

Design and methods: In a prospective study, based in general practice, formerly undiagnosed subjects $(n=464)$ were assessed at baseline and at 5 years for respiratory symptoms and pulmonary function. Odds ratios for early signs were calculated (adjusted for age, gender, pack-years at baseline and smoking behaviour during follow-up), and defined as possible indicators of disease progression.
\end{abstract}

Results: Over a 5 year period, the percentage of subjects with obstruction increased from $7.5 \%(n=35)$ at baseline to $24.8 \%(n=115)$ at 5 years. The presence of mild early signs and lung function below the normal range at baseline were related to an increased risk of developing mild to moderate COPD (GOLD I: OR 1.87 (95\% Cl 1.22 to 2.87); GOLD II: OR 2.08 ( $95 \% \mathrm{Cl} 1.29$ to 3.37 ) to 2.54 (95\% Cl 1.25 to 5.19$)$ ) at 5 years.

Conclusion: Lung function below the normal range and early respiratory signs predict the development and progression of COPD.

In the past decades, an increase in the prevalence of chronic obstructive pulmonary disease (COPD) and asthma has been observed. ${ }^{2}$ As a result of demographic changes, the global burden of COPD is expected to shift from the sixth leading cause of death in 1990 to third position by 2020. ${ }^{3}$ This evolution is a significant challenge for primary care, as the prevalence of COPD is expected to nearly double over the period 1994-2015.. ${ }^{5}$

Although it is generally recognised that patients with COPD should be identified before the disease becomes substantial, early stage COPD often remains undiagnosed ${ }^{6}$ or misdiagnosed. ${ }^{7}$ To decrease morbidity and mortality from this chronic lung disorder, the Global Initiative for Chronic Obstructive Lung Disease (GOLD) programme was initiated. ${ }^{8}$ In a number of cross sectional, population based surveys, ${ }^{9-11}$ the GOLD guidelines were used to estimate the prevalence of COPD. One of the first surveys, the confronting COPD International Survey, ${ }_{1}^{12}$ confirmed the huge burden to society and, furthermore, identified a significant disparity between subjects' perception of disease severity and the assessed degree of severity.

The hallmark of COPD is the presence of airway obstruction. Recently, the prevalence of undiagnosed airflow obstruction was estimated by reviewing data from 13 (mainly cross sectionally designed) studies. ${ }^{13}$ Prevalence ranged from $3 \%$ to $12 \%$. Furthermore, the GOLD guidelines define a very early stage of COPD, in which subjects are considered to be "at risk" for COPD. ${ }^{14}$ This so-called GOLD stage 0 is defined by chronic respiratory symptoms without measurable obstruction. Meanwhile, prospective long term and population based studies, focusing on early stage COPD in relation to respiratory disease years later, are scarce. ${ }^{10}{ }^{15}$ In one study, ${ }^{10}$ the Copenhagen City Heart Study, the authors concluded that GOLD stage 0 was not prognostic for the development of COPD. In the Obstructive Lung Disease in Northern Sweden study, ${ }^{15}$ subjects with respiratory symptoms at study entry showed an increased risk of developing COPD. As this ambiguity warrants further research, the objective of the current study was to investigate the value of early respiratory symptoms and lung function below the normal range as indicators for progression of COPD.

\section{METHODS}

\section{Design}

The Detection, Intervention and Monitoring of COPD and Asthma in general practice (DIMCA study) is a prospective cohort study, designed to assess the feasibility of active detection of early stage chronic respiratory disease (COPD, asthma) in the Dutch general population ${ }^{16}$ (fig 1). The initial cohort can be regarded as a random sample from the Dutch general population. Adult subjects (20-70 years) without a medical history of COPD, asthma or other chronic respiratory disease were included. All subjects took part in a screening programme for COPD or asthma at the earliest possible stage of disease. The assessment consisted of a respiratory symptoms questionnaire and lung function measurement. The criteria in the original screening programme, further referred to as early signs of respiratory morbidity, ${ }^{i}$ were used to define the baseline respiratory status of screened subjects. Subjects with either respiratory symptoms, lung function below the normal range ${ }^{17}$ or a response on salbutamol (reversibility) at baseline were considered to have an increased risk of developing respiratory morbidity. Otherwise, subjects were labelled as having no abnormalities. Subsequently, at risk subjects were invited to participate in a 
2 year monitoring programme. After monitoring, those showing persistent signs and symptoms (of varying severity) were invited for an intervention study with inhaled corticosteroids in a series of three randomised controlled trials. The results of the trials are described elsewhere. ${ }^{18-20}$

For the present study, subjects were reassessed after 5 years with regard to their respiratory symptoms and lung function. Invited were the following: all subjects with an increased risk of developing respiratory morbidity who participated in monitoring $(\mathrm{n}=384)$ and a random sample of subjects with no baseline abnormalities ( $n=199$ ) (fig 1$)$.

The course of respiratory morbidity was operationalised by the change in lung function, reversibility, respiratory symptoms and self-reported smoking behaviour over the 5 year period. Subjects were classified by COPD stages, as the recently developed GOLD guidelines ${ }^{21}$ facilitate such classification. To study whether early signs and symptoms of respiratory morbidity precede development of actual disease, an algorithm based on the GOLD criteria (table 1) was used to allocate subjects to one of the following categories: asthmatic, at risk for COPD (GOLD 0), mild COPD (GOLD I), moderate COPD (GOLD II), severe COPD (GOLD III) or no COPD or asthma.

The medical ethics review board of the University Medical Centre Nijmegen approved the study. Subjects gave their written informed consent.

\section{Measurements}

\section{Lung function and reversibility}

Lung function was assessed by two trained lung function technicians at two different points in time (at baseline and at
5 years). Measurements were performed according to the American Thoracic Society standards. ${ }^{22}$ ECCS reference values were used. ${ }^{23}$ Variation in spirometer performance was assessed and accounted for. Reversibility ${ }^{24}$ was assessed 15 min after inhalation of $800 \mu \mathrm{g}$ of salbutamol by spacer. At the moment of screening, lung function below the normal range ${ }^{17}$ was defined as bronchodilator forced expiratory volume in $1 \mathrm{~s} / \mathrm{vital}$ capacity $\left(\mathrm{FEV}_{1} / \mathrm{VC}\right)$ less than or equal to the lower limit of normal (predicted minus 1.64 SD). Reversibility was defined as positive if after bronchodilatation the change in $\mathrm{FEV}_{1}$ (relative to the predicted value) was at least $15 \% .{ }^{24}$ In the GOLD based disease classification, ${ }^{21}$ definitions were for obstruction, a post-bronchodilator $\mathrm{FEV}_{1} / \mathrm{VC}<70 \%$, and for reversibility, a $12 \%$ change in predicted $\mathrm{FEV}_{1}$ after bronchodilatation with a change of at least $200 \mathrm{ml}$.

\section{Respiratory symptoms and smoking behaviour}

The occurrence of respiratory symptoms was measured at baseline and at 5 years with the Dutch modified version of the Medical Research Council questionnaire. ${ }^{25}$ Chronicity of respiratory symptoms was defined by occurrence of symptoms for more than 3 months per year. Mucus hypersecretion was defined as continuous production of sputum in the winter season. Furthermore, subjects were asked whether they were current smokers, ex-smokers or never smokers.

\section{Statistical analysis}

To describe the course of respiratory morbidity, the mean individual change over the 5 year follow-up period in lung function was compared for the group of subjects with no

Figure 1 Flow chart of the initial general population cohort in the Detection, Intervention and Monitoring of COPD and Asthma in general practice (DIMCA study) program, and the follow-up group reassessed at 5 years. ${ }^{*} 12 \%(n=239)$ were excluded because respiratory disease had already been diagnosed by their general practitioner. $\uparrow$ At 5 years, the follow-up cohort was reduced, leaving 400 subjects in the at-risk group and 200 subjects in the group without respiratory abnormalities. \$Total number of 145 at risk subjects participated in one of the randomised controlled trials. ${ }^{1820} 39$

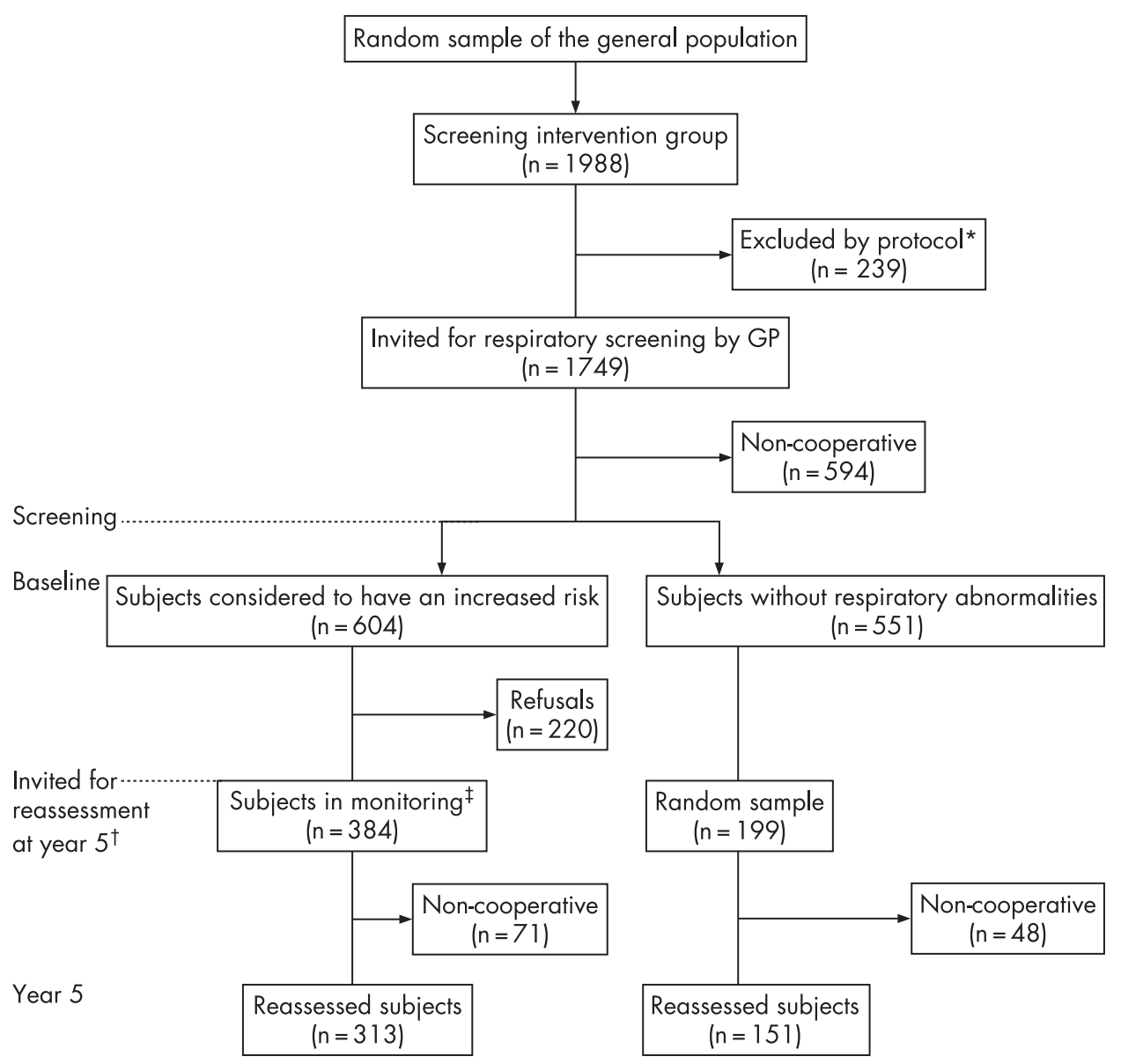


Table 1 Algorithm for the classification of chronic respiratory disease (based on the GOLD criteria ${ }^{21}$ )

\begin{tabular}{|c|c|c|c|}
\hline Lung function & Respiratory symptoms* & Reversibility $\dagger$ & Disease classification \\
\hline \multirow[t]{3}{*}{ No obstruction: } & & Yes & Asthmatic \\
\hline & No chronic symptoms & No & No COPD or asthma \\
\hline & Chronic symptoms & No & At risk for COPD (GOLD 0) \\
\hline \multicolumn{2}{|l|}{ Obstruction: } & Yes & Inadequately managed asthma \\
\hline \multicolumn{2}{|l|}{ and $\mathrm{FEV}_{1} \S \geqslant 80 \%$} & No & Mild COPD (GOLD I) \\
\hline \multicolumn{2}{|l|}{ or $50 \% \leqslant \mathrm{FEV}_{1}<80 \%$} & No & Moderate COPD (GOLD II) \\
\hline \multicolumn{2}{|l|}{ or $30 \% \leqslant \mathrm{FEV}_{1}<50 \%$} & No & Severe COPD (GOLD III) \\
\hline \multicolumn{4}{|c|}{$\begin{array}{l}{ }^{*} \text { Chronic symptoms: cough and sputum production for at least } 3 \text { months in each of two consecutive years. } \\
\text { † Reversibility: a } 12 \% \text { change in predicted } \mathrm{FEV}_{1} \text { after bronchodilatation with a change of at least } 200 \mathrm{ml} \text {. } \\
\text { tObstructive if } \mathrm{FEV}_{1} / \text { vital capacity }<70 \% \text {. } \\
\S \text { Post-bronchodilator forced expiratory volume. } \\
\text { COPD, chronic obstructive pulmonary disease; } \mathrm{FEV}_{1} \text {, forced expiratory volume in } 1 \mathrm{~s} \text {; GOLD, Global Initiative for Chronic Obstructive } \\
\text { Lung Disease. }\end{array}$} \\
\hline
\end{tabular}

abnormalities versus the group of at risk subjects. The appropriate univariate statistical tests were used.

Progression of COPD was studied using multinomial logistic modelling. The dependent variable was respiratory morbidity at 5 years. This outcome was defined by the three categories of absence of COPD or asthma, mild COPD or moderate to severe COPD. Initially obstructed subjects were excluded from the analysis. Odds ratios (OR) of early signs of respiratory morbidity were calculated and defined as possible indicators of disease progression. Because of gained insight, mucus hypersecretion was added to the signs initially defined at the screening. ORs were based on adjustment for age, gender, number of packyears at baseline and smoking behaviour during the 5 year follow-up period. Following disease classification at 5 years (table 1), categories were compared on lung function and obstruction over the 5 years using confidence limits. The SAS statistical package (V8.2 for Windows) was used for all analyses. Two sided $p$ values of $<0.05$ were considered to be statistically significant.

\section{RESULTS}

The flow of the DIMCA cohort (fig 1; $\mathrm{n}=1749$ ) showed different rates of non-participation. Over the 5 year period, 10 subjects were lost to follow-up because of death (none was COPD related). Between the initial (screened) sample and the (on GOLD stage) classified sample at 5 years there were no signs of selection (dropout, trial participants ${ }^{\mathrm{iii}}$ ). A total of 583 subjects were invited for reassessment at 5 years. In the group without respiratory abnormalities $(n=199)$, the response was $76 \%$; in the at risk group $(n=384)$, the response was $82 \%$.

\section{Symptoms and lung function in screened subjects}

The characteristics of the study population, and their evolution over the 5 year period, are given in table 2. At baseline, there was no difference in age, gender, height or smoking history between subjects without respiratory abnormalities and at risk subjects. Both at baseline and at the reassessment after 5 years, at risk subjects had more symptoms $(p=0.001)$, lower post-bronchodilator $\mathrm{FEV}_{1}(\mathrm{p}=0.0001)$ and lower post-bronchodilator $\mathrm{FEV}_{1} / \mathrm{VC}$

Table 2 Characteristics of the study population

\begin{tabular}{|c|c|c|c|c|}
\hline & \multicolumn{4}{|c|}{ Screened subjects } \\
\hline & \multicolumn{2}{|c|}{$\begin{array}{l}\text { Without baseline abnormalities } \\
\text { ( } n=151)\end{array}$} & \multicolumn{2}{|c|}{$\begin{array}{l}\text { With baseline abnormalities } \\
(\mathrm{n}=313)\end{array}$} \\
\hline & Year 0 & Year 5 & Year 0 & Year 5 \\
\hline Age & $42.9(11.2)$ & $48.0(11.2)$ & $44.0(11.5)$ & $49.2(11.5)$ \\
\hline Gender ( $\%$ female) & 50.3 & 50.3 & 59.4 & 59.4 \\
\hline $\mathrm{FEV}_{1}^{*}(\mathrm{ml})$ & 3532 (833) & $3335(806)$ & $3195(795)$ & $2938(802)$ \\
\hline $\mathrm{FEV}_{1} \mathrm{NC}(\%)$ & $84.5(8.3)$ & $79.3(7.9)$ & $81.3(9.8)$ & $73.0(8.8)$ \\
\hline \multicolumn{5}{|l|}{ Screening criteria $†$} \\
\hline Respiratory symptoms & - & 37.1 & 88.8 & 80.5 \\
\hline Lung function $<$ normal range§ & - & 4.6 & 16.6 & 20.8 \\
\hline Reversibility & - & 0.7 & 2.9 & 2.9 \\
\hline Mild early signs** & - & 9.3 & 31.6 & 32.6 \\
\hline Mucus hypersecretion $\uparrow \dagger$ & 0.7 & 4.6 & 14.4 & 13.7 \\
\hline Pack-years & $8.9(12.0)$ & & $8.7(10.8)$ & \\
\hline Ever smokers (\%) & 43.1 & 43.7 & 32.6 & 34.2 \\
\hline Current smokers (\%) & 31.8 & 27.2 & 40.6 & 36.7 \\
\hline
\end{tabular}

\footnotetext{
Values are mean (SD).

*Post-bronchodilator FEV 1 (at 5 years: $n=150$ and $n=299$, respectively).

$\uparrow$ Screening criteria, used to determine the respiratory status of subjects (see table $A 1$ in appendix 1).

tDutch modified version of the Medical Research Council questionnaire.

$\S F E V_{1} / N C \leqslant$ lower limit of normal.

$\checkmark 15 \%$ predicted.

**Combination of at least two out of three mild early signs (mild obstruction or reversibility, or a weather dependent cough or shortness of breath, or a recurrent productive cough).

$\uparrow$ Continuous production of sputum in the winter season.

COPD, chronic obstructive pulmonary disease; $\mathrm{FEV}_{1}$, forced expiratory volume in $1 \mathrm{~s}$; VC, vital capacity.
} 
Table 3 Obstruction and respiratory morbidity

\begin{tabular}{|c|c|c|c|c|}
\hline & \multicolumn{2}{|c|}{ Obstructed subjects } & \multirow{2}{*}{$\frac{\text { Respiratory morbidity }}{5 \text { years n }(\%)}$} & \multirow{2}{*}{$\begin{array}{l}\text { Subject to } \\
\text { analysis (n) }\end{array}$} \\
\hline & Baseline (n) & 5 years $(n)$ & & \\
\hline No COPD or asthma & 9 & & $296(63.8)$ & 287 \\
\hline Mild COPD & 12 & 60 & $60(12.9)$ & 48 \\
\hline Moderate COPD & 10 & 49 & $49(10.6)$ & 39 \\
\hline At risk for COPD & 1 & & $7(1.5)$ & \\
\hline Asthmatic & 3 & 6 & $21(4.5)$ & \\
\hline Missing & & & $31(6.7)$ & \\
\hline Total & 35 & 115 & $464(100)$ & 374 \\
\hline
\end{tabular}

COPD, chronic obstructive pulmonary disease.

( $p=0.0003$ and $p<0.0001$, respectively), and were more often current smokers ( $p=0.07$ and $p=0.04$, respectively) than subjects without baseline abnormalities. Over the 5 year period, the overall individual change $(n=464)$ showed a decrease in postbronchodilator $\mathrm{FEV}_{1}(-241$ (SD 303) $\mathrm{ml}$; on average, $-48 \mathrm{ml}$ / year) and in post-bronchodilator $\mathrm{FEV}_{1} / \mathrm{VC}(7.1 \%$ (SD 9.9\%)). At risk subjects demonstrated more reduction in lung function (post-bronchodilator $\mathrm{FEV}_{1}-262 \mathrm{ml}$ vs $-199 \mathrm{ml} ; \mathrm{p}=0.02$ ) and a lower average post-bronchodilator $\mathrm{FEV}_{1} / \mathrm{VC}(-8.0$ vs -5.2 ; $\mathrm{p}=0.04)$.

\section{Respiratory morbidity}

The distribution of respiratory morbidity at 5 years is presented in table 3 . Over the 5 year period, the percentage of subjects
Figure 2 The course of forced expiratory volume in $1 \mathrm{~s}\left(\mathrm{FEV}_{1}\right)$ and $\mathrm{FEV}_{1} /$ vital capacity $\left(\mathrm{FEV}_{1} / \mathrm{VC}\right)$ in early respiratory morbidity. Values are mean $(95 \% \mathrm{CI}) .{ }^{*}$ Statistically significant difference between year 0 and year 5 .
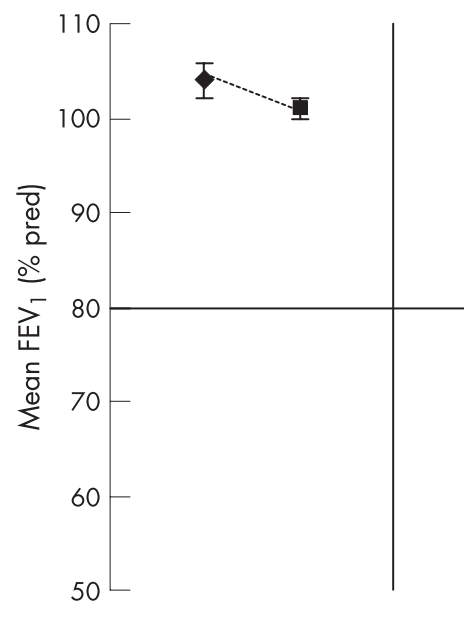

Post-bronchodilator $\mathrm{FEV}_{1}(95 \% \mathrm{Cl})$
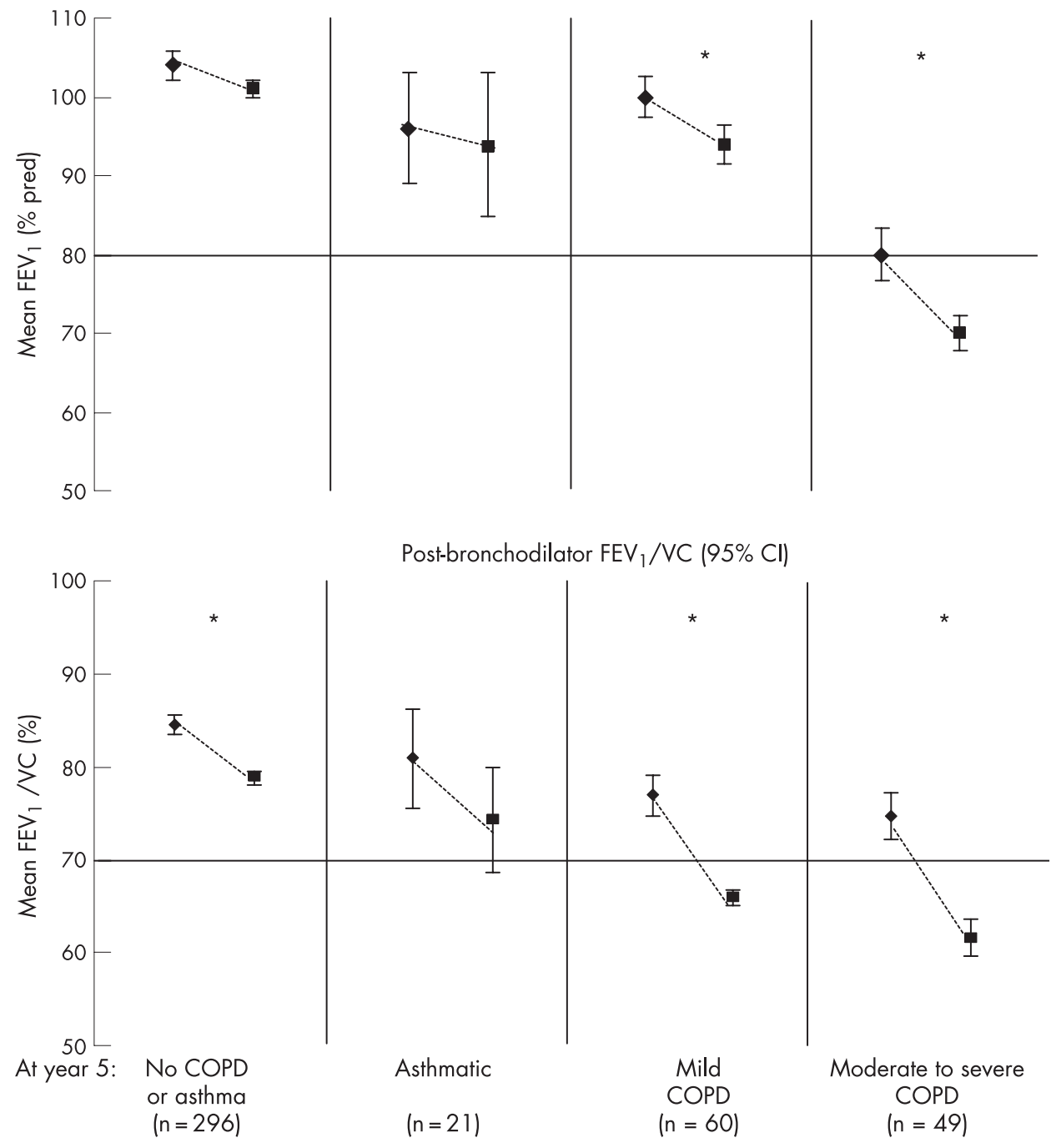
Table 4 Odds ratios from multinomial regression analysis of early signs as predictors of respiratory morbidity 5 years later

\begin{tabular}{|c|c|c|c|c|}
\hline & \multicolumn{4}{|c|}{ Respiratory morbidity $\uparrow$ at 5 years $(n=374)$} \\
\hline & \multicolumn{2}{|l|}{ Mild COPD (12.8\%) } & \multicolumn{2}{|c|}{ Moderate COPD (10.4\%) } \\
\hline & $\mathbf{O R}$ & Adjusted OR & $\mathbf{O R}$ & Adjusted OR \\
\hline \multicolumn{5}{|l|}{ Screening criteria* } \\
\hline Respiratory symptoms $\ddagger$ & $1.30[0.92$ to 1.83$]$ & $1.41[0.98$ to 2.01$]$ & $0.96[0.66$ to 1.42$]$ & $0.94[0.61$ to 1.43$]$ \\
\hline Lung function below normal range§ & $1.45[0.74$ to 2.86$]$ & $1.46[0.72$ to 2.96$]$ & $2.02[1.07$ to 3.83$]$ & $2.54[1.25$ to 5.19$]$ \\
\hline Reversibility & $1.04[0.38$ to 2.88$]$ & $1.02[0.00$ to 0.03$]$ & $0.56[0.16$ to 1.93$]$ & $0.94[0.25$ to 3.49$]$ \\
\hline Mild early signs ${ }^{* *}$ & $1.69[1.13$ to 2.54$]$ & $1.87[1.22$ to 2.87$]$ & $1.97[1.28$ to 3.02$]$ & $2.08[1.29$ to 3.37$]$ \\
\hline Mucus hypersecretiont† & $1.35[0.77$ to 2.36$]$ & $1.17[0.64$ to 2.14$]$ & $2.53[1.52$ to 4.19$]$ & $1.88[1.07$ to 3.33$]$ \\
\hline \multicolumn{5}{|l|}{ Smoking behaviour } \\
\hline Pack-years (baseline) & & $0.99[0.95$ to 1.02$]$ & & $1.05[1.01$ to 1.08$]$ \\
\hline Not smoking at 5 years & & $1.23[0.79$ to 1.92$]$ & & $1.04[0.56$ to 1.90$]$ \\
\hline Smoking at 5 years & & $1.53[0.96$ to 2.46$]$ & & $1.81[0.99$ to 3.30$]$ \\
\hline Smoking during follow-up & & $1.31[0.54$ to 3.17$]$ & & $0.79[0.21$ to 2.96$]$ \\
\hline Age & & $1.00[0.97$ to 1.04$]$ & & $1.06[1.01$ to 1.10$]$ \\
\hline Gender (female $=1$ ) & & $0.54[0.38$ to 0.76$]$ & & $1.13[0.73$ to 1.73$]$ \\
\hline \multicolumn{5}{|c|}{ 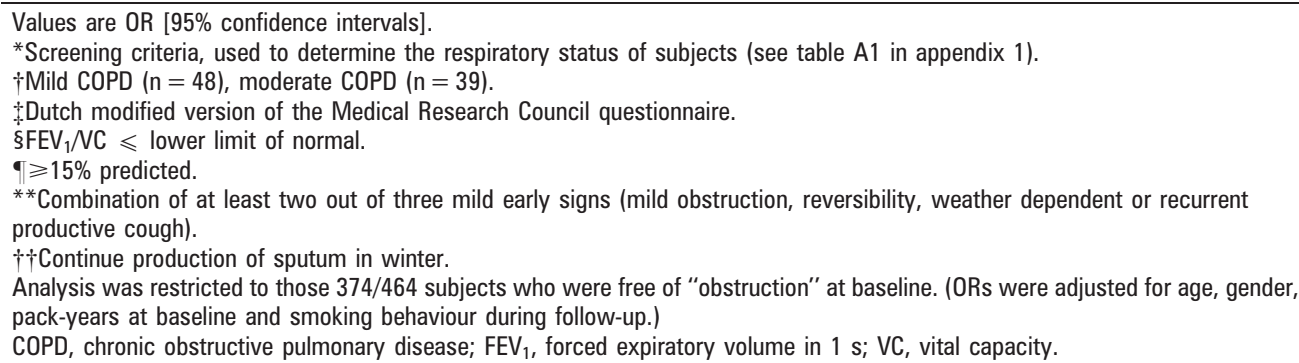 } \\
\hline
\end{tabular}

with obstruction increased from $7.5 \%(n=35)$ at baseline to $24.8 \%(n=115)$ at 5 years. The change in lung function (postbronchodilator $\mathrm{FEV}_{1}$ ) and obstruction over the 5 year period is presented in fig 2. The group of subjects labelled at 5 years as not having COPD or asthma $(n=296)$ did not show a decline in lung function. There was a slight but significant decrease in post-bronchodilator $\mathrm{FEV}_{1} / \mathrm{VC}$, but subjects did not become obstructive. Asthmatic subjects at 5 years $(n=21)$ showed no decrease in lung function or post-bronchodilator $\mathrm{FEV}_{1} / \mathrm{VC}$. Over the 5 year period, subjects with mild COPD $(n=60)$ or moderate to severe COPD $(n=49)$ had significantly decreased lung function and also became obstructive.

\section{Respiratory morbidity odds ratios}

Assessment of respiratory morbidity at 5 years included 464 subjects (table 3 ). The multinomial logistic regression analysis focused on subjects without COPD or asthma $(n=287)$, mild COPD subjects $(n=48)$ and moderate to severe COPD subjects $(n=39)$. Subjects with obstruction at baseline $(n=35)$ were excluded from the analysis. ORs for early signs of respiratory morbidity were adjusted for age, gender, number of pack-years at baseline and smoking behaviour (table 4). Results showed that subjects with a baseline presence of mild obstruction or reversibility, or a weather dependent cough or shortness of breath, or a recurrent productive cough had an increased risk of developing mild COPD (OR 1.87) or moderate COPD (OR 2.08). The presence of lung function below the normal range and

iScreening criteria, used to determine the respiratory status of subjects (see table A1 in appendix 1).

"Baseline values of the several follow-up groups (see table A2 in appendix 1).

iiiTrial participants. mucus hypersecretion at baseline appeared to be predictive of the development of moderate COPD (OR 2.54 and OR 1.88, respectively). Female gender was significantly underrepresented in mild COPD (OR 0.54) whereas older age (OR 1.06) and an increased smoking history contributed to the risk of development of moderate COPD (OR 1.06 and OR 1.05, respectively).

\section{DISCUSSION}

The main objective of the current study was to investigate the value of early respiratory symptoms and lung function below the normal range as indicators of progression of COPD. During the study period, we observed a substantial increase in morbidity in subjects who at baseline were considered to have an increased risk for development of chronic obstructive airway disease. The most prominent predictors for developing COPD were lung function below the normal range and mild early signs of reversibility, weather dependent cough or shortness of breath or recurrent productive cough. ${ }^{\mathrm{i}}$

COPD appears to be an insidious disease at the start. Because of subjects' lack of perception of disease severity, ${ }^{12}$ there is enormous under-presentation of early signs of respiratory morbidity ${ }^{26}$ causing underdiagnosis of COPD in general practice. As smoking cessation can reduce symptoms and prevent progression of disease, ${ }^{27}$ early detection is important. Additional reasons to promote early detection is that treatment of COPD can improve lung function and quality of life in many patients, can reduce admissions to hospital and may even improve survival. ${ }^{27}$ Spirometry is considered the "gold standard" for detecting obstruction, and also provides prognostic information. ${ }^{1128}$. As yet, mass screening for obstruction is not considered feasible in general practice ${ }^{13}$ and until now there has been no long term evidence on its effectiveness. Several studies focused on screening of high risk groups, ${ }^{29}{ }^{30}$ but this will only detect part of the population with obstruction. ${ }^{31}$ For 
reasons of feasibility and cost effectiveness, it is generally agreed that case finding is the most appropriate tool in reducing underdiagnosis of COPD in general practice. As a first step in the development of an evidence based model for case finding, risk factors for the detection of early COPD need to be identified. Development of COPD was investigated in several studies, ${ }^{32-36}$ in which a great variety of risk factors (such as middle age, current or past smoking status, a self reported history or a general physician's diagnosis of chronic obstructive airway disease, laryngeal height, bronchial hyperresponsiveness, respiratory symptoms, body mass index, accelerated decline in lung function, exercise capacity, occupational exposure, air pollution, asthma, genetic variation and functional status) were used.

In the present study, in a population based sample with initially undiagnosed subjects from general practice, we used prospective data to describe early development of COPD, and to identify risk factors. We used an algorithm, based on the recently developed GOLD guidelines, to relate disease severity at 5 years to the baseline presence of early signs. However, there are several points to raise. Firstly, in the study design, the early signs were fixed by the screening criteria defined at baseline. Because of gained insight, mucus hypersecretion (prominent in former GOLD stage 0 ) was added to this selection of early signs. Secondly, subjects were classified on the basis of a cross sectional measurement at 5 years. Although a well defined algorithm was used, classification was only based on postbronchodilator $\mathrm{FEV}_{1}, \mathrm{VC}$, reversibility and respiratory symptoms. In daily practice, however, often additional clinical assessment will be needed to arrive at an undisputed diagnosis, with a reliable disease staging. On the other hand, in the present study, reversibility data were used to distinguish between COPD and asthma. Development of COPD was further confirmed by progressive lung function decline and development of obstruction (fig 2). In their study of the population impact of different definitions of airway obstruction, Celli and colleagues $^{11}$ stated that the rates according to the GOLD guidelines were found to produce lower estimates than other spirometry based definitions. This may be explained by the fact that in that study, spirometry was performed only prebronchodilator. ${ }^{37}$ Celli et al did not have disposition of reversibility testing, making it impossible to distinguish reversible from irreversible obstruction. ${ }^{11}$ In a recent editorial, ${ }^{38}$ Vestbo indicated that GOLD has not attempted to separate 0 COPD from symptomatic asthma. With the algorithm used, including an effort to minimise mislabelling of asthmatic subjects, we used a prudent estimate of prevailing disease at 5 years. Thirdly, as in regression analysis, adjustment was restricted to a limited set of risk factors (age, gender, pack-years at baseline and smoking behaviour during follow-up) and not all confounding factors may have been excluded. A further finding concerned the steady (or slightly decreased) percentage of subjects with respiratory signs and symptoms in the at risk group. The most obvious explanation might be that after assessment of symptoms, the problem is identified and subjects will deal with it.

Over the 5 year period, the number of subjects with obstruction increased considerably. In other terms, screened subjects, considered to have an increased risk for development of COPD, appeared to have a more than threefold risk of actually developing mild or moderate COPD. The most prominent predictor for development of moderate COPD was a baseline presence of lung function below the normal range (OR 2.54). In this cohort of initially undiagnosed subjects, a baseline presence of mild obstruction or reversibility, or a weather dependent cough or shortness of breath, or a recurrent productive cough were predictive for the development of mild COPD (OR 1.87) or moderate COPD (OR 2.08) 5 years later. Furthermore, baseline mucus hypersecretion (in the absence of airflow obstruction without full reversibility) appeared to be predictive (OR 1.88) for subsequent development of moderate COPD. A prolonged follow-up from early stage COPD onwards, followed by an undisputed clinical diagnosis, may further clarify these relations. In terms of healthcare, identification of risk factors for early detection of COPD may contribute to the development of an evidence based model for case finding. This is specifically of interest for the studied cohort, as these undiagnosed subjects did not present themselves in primary care.

In conclusion, lung function below the normal range and early respiratory signs are possible predictors of progression of COPD. As a result, implementation of GOLD guidelines in general practice may reduce underdiagnosis and under treatment.

Acknowledgements: The authors thank Guido van den Boom. His former support and contribution were critical to the present article. The authors also wish to thank Lea Peters and Joke Grootens for their support in data collection, logistics and generating graphs.

Competing interests: None.

Ethics approval: Yes.

\section{REFERENCES}

1. Lofdahl CG. Cost development of obstructive airway disease in Sweden. Eur Respir Rev 1996;6:113-15

2. Tirimanna PR, van Schayck CP, den Otter JJ, et al. Prevalence of asthma and COPD in general practice in 1992: has it changed since 1977? Br J Gen Pract 1996;46:27781.

3. Murray CJL, Lopez AD. Alternative visions of the future: projecting mortality and disability, 1990-2020. In: Murray CJL, Lopez AD, eds. The Global Burden of Disease. The Harvard School of Public Health, on behalf of the World Health Organization and the World Bank, 1996:361-95.

4. Weel CV, Smith H, Beasley JW. Family practice research networks. Experience from three countries. J Fam Pract 2000;49:938-43.

5. Feenstra TL, van Genugten ML, Hoogenveen RT, et al. The impact of aging and smoking on the future burden of chronic obstructive pulmonary disease: a model analysis in the Netherlands. Am J Respir Crit Care Med 2001;164:590-6.

6. Coultas DB, Mapel D, Gagnon R, et al. The health impact of undiagnosed airflow obstruction in a national sample of United States adults. Am J Respir Crit Care Med 2001;164:372-7.

7. Tinkelman DG, Price DB, Nordyke RJ, et al. Misdiagnosis of COPD and asthma in primary care patients 40 years of age and over. J Asthma 2006;43:75-80.

8. Pauwels RA, Buist AS, Calverley PM, et al. Global strategy for the diagnosis, management, and prevention of chronic obstructive pulmonary disease. NHLBI/WHO Global Initiative for Chronic Obstructive Lung Disease (GOLD) Workshop summary. Am J Respir Crit Care Med 2001;163:1256-76.

9. de Marco R, Accordini S, Cerveri l, et al. An international survey of chronic obstructive pulmonary disease in young adults according to GOLD stages. Thorax 2004;59:120-5

10. Vestbo J, Lange P. Can GOLD stage 0 provide information of prognostic value in chronic obstructive pulmonary disease? Am J Respir Crit Care Med 2002;166:32932.

11. Celli BR, Halbert RJ, Isonaka S, et al. Population impact of different definitions of airway obstruction. Eur Respir J 2003;22:268-73.

12. Rennard S, Decramer M, Calverley PM, et al. Impact of COPD in North America and Europe in 2000: subjects' perspective of Confronting COPD International Survey. Eur Respir J 2002;20:799-805.

13. Coultas DB, Mapel DW. Undiagnosed airflow obstruction: prevalence and implications. Curr Opin Pulm Med 2003;9:96-103.

14. Fabbri LM, Hurd SS. Global Strategy for the diagnosis, management and prevention of COPD: 2003 update. Eur Respir J 2003;22:1-2.

15. Lindberg A, Eriksson B, Larsson LG, et al. Seven-year cumulative incidence of COPD in an age-stratified general population sample. Chest 2006;129:879-85.

16. Van den Boom G, van Schayck CP, Van Molken MP, et al. Active detection of chronic obstructive pulmonary disease and asthma in the general population. Results and economic consequences of the DIMCA program. Am J Respir Crit Care Med 1998;158:1730-8.

17. Pellegrino R, Viegi G, Brusasco V, et al. Interpretative strategies for lung function tests. Eur Respir J 2005;26:948-68. 
18. van Grunsven P, Schermer T, Akkermans R, et al. Short- and long-term efficacy of fluticasone propionate in subjects with early signs and symptoms of chronic obstructive pulmonary disease. Results of the DIMCA study. Respir Med 2003;97:1303-12.

19. van den BG, Rutten-van Molken MP, Molema J, et al. The cost effectiveness of early treatment with fluticasone propionate 250 microg twice a day in subjects with obstructive airway disease. Results of the DIMCA program. Am J Respir Crit Care Med 2001;164:2057-66.

20. Albers $\mathbf{M}$, Schermer T, Van den Boom G, et al. Efficacy of inhaled steroids in undiagnosed subjects at high risk for COPD. Results of the detection, intervention, and monitoring of COPD and asthma program. Chest 2004;126:1815-24.

21. Global Initiative for Chronic Obstructive Lung Disease (GOLD) www.goldcopd.com (accessed 1 December 2007).

22. Standardization of Spirometry, 1994 Update. American Thoracic Society. Am J Respir Crit Care Med 1995;152:1107-36.

23. Quanjer PH, Tammeling GJ, Cotes JE, et al. Lung volumes and forced ventilatory flows. Report Working Party Standardization of Lung Function Tests, European Community for Steel and Coal. Official Statement of the European Respiratory Society. Eur Respir J Supp/ 1993;16:5-40.

24. Peat JK, Woolcock AJ, Cullen K. Rate of decline of lung function in subjects with asthma. Eur J Respir Dis 1987;70:171-9.

25. van Schayck CP, Folgering $\mathrm{H}$, den Otter $\mathrm{JJ}$, et al. Does the continuous use of bronchodilators mask the progression of asthma or chronic bronchitis? Fam Pract 1992;9:397-404.

26. Boom GVD, Tirimanna PRS, Kaptein AA, et al. Underpresentation of shortness of breath in the general population. Results of the DIMCA programme. Asthma Gen Pract 1999;7:3-7.

27. Rennard SI. Treatment of stable chronic obstructive pulmonary disease. Lancet 2004;364:791-802

28. Buffels J, Degryse J, Heyrman J, et al. Office spirometry significantly improves early detection of COPD in general practice: the DIDASCO Study. Chest 2004;125:1394-9.

29. Zielinski J, Bednarek M. Early detection of COPD in a high-risk population using spirometric screening. Chest 2001;119:731-6.

30. Stratelis G, Jakobsson P, Molstad S, et al. Early detection of COPD in primary care: screening by invitation of smokers aged 40 to 55 years. Br J Gen Pract 2004;54:2016.

31. Albers $\mathbf{M}$, Thoonen B, Dekhuijzen R. Recommended case-finding strategy misclassifies relevant groups of subjects with COPD. Rapid response to: van Schayck $\mathrm{CP}$, Loozen JMC, Wagena $\mathrm{E}$, et al. Detecting patients at a high risk of developing chronic obstructive pulmonary disease in general practice: cross sectional case finding study. BMJ 2002;324:1370.
32. Celli BR, Cote CG, Marin JM, et al. The body-mass index, airflow obstruction, dyspnea, and exercise capacity index in chronic obstructive pulmonary disease. N Engl J Med 2004;350:1005-12.

33. Hospers JJ, Postma DS, Rijcken B, et al. Histamine airway hyper-responsiveness and mortality from chronic obstructive pulmonary disease: a cohort study. Lancet 2000;356:1313-17.

34. Straus SE, McAlister FA, Sackett DL, et al. The accuracy of patient history, wheezing, and laryngeal measurements in diagnosing obstructive airway disease. CARE-COAD1 Group. Clinical Assessment of the Reliability of the Examination-Chronic Obstructive Airways Disease. JAMA 2000;283:1853-7.

35. Mannino DM. Chronic obstructive pulmonary disease: definition and epidemiology Respir Care 2003;48:1185-91.

36. Rijcken B, Schouten JP, Xu X, et al. Airway hyperresponsiveness to histamine associated with accelerated decline in FEV1. Am J Respir Crit Care Med 1995:151:1377-82.

37. Sterk PJ. Let's not forget: the GOLD criteria for COPD are based on postbronchodilator FEV1. Eur Respir J 2004;23:497-8.

38. Vestbo J. COPD in the ECRHS. Thorax 2004:59:89-90.

39. van den BG, Rutten-van Molken MP, Molema J, et al. The cost effectiveness of early treatment with fluticasone propionate 250 microg twice a day in subjects with obstructive airway disease. Results of the DIMCA program. Am J Respir Crit Care Med 2001;164:2057-66.

\section{APPENDIX}

\section{Appendix 1}

Table A1 shows the screening criteria used to determine respiratory status of subjects and table A2 shows the baseline values of the respective follow-up groups

\section{Appendix 2}

A total number of 145 at risk subjects participated in one of the randomised controlled trials (for a period varying between 12 and 30 months), in which inhaled corticosteroids ( $n=68$ ) were compared with placebo treatment $(n=77)$. The mean individual change in post-bronchodilator $\mathrm{FEV}_{1}$ over the 5 year period was $-352 \mathrm{ml}$ (SD 287) in the corticosteroid treated group versus $-280 \mathrm{ml}$ (SD 307) in the placebo treated group. Based on the individual change over the 5 year period, corticosteroid treatment did not show a different course in respiratory symptoms, postbronchodilator $\mathrm{FEV}_{1}(p=0.09)$ or post-bronchodilator $\mathrm{FEV}_{1} \mathrm{NC}(\mathrm{p}=0.96)$ from placebo treatment. As a consequence, participants in the intervention study were included in the sample.

Table A1 Screening criteria used to determine the respiratory status of subjects

\begin{tabular}{ll}
\hline Criteria & \\
\hline Respiratory symptoms & $\begin{array}{l}\text { Wheezing, dyspnoea, cough ( } \geqslant 3 \text { months/year) or an asthma attack or } \\
\text { shortness of breath due to an allergic reaction (in the previous } 12 \text { months) }\end{array}$ \\
$\begin{array}{l}\text { Lung function below the normal range } \\
\text { Reversibility }\end{array}$ & $\mathrm{FEV}_{1} / \mathrm{NC} \leqslant$ lowersibility $\geqslant 15 \%$ predicted \\
(at least two out of three) mild early signs & $\mathrm{FEV}_{1} / \mathrm{VC} \leqslant$ predicted value minus $1 \mathrm{SD}$ and/or \\
& $\mathrm{FEV}_{1}$ reversibility $\geqslant 10 \%$ predicted and/or \\
& weather dependent (productive) cough or shortness of breath or the occurrence \\
& of more than one period of (productive) cough in the previous two years
\end{tabular}

$\mathrm{FEV}_{1}$, forced expiratory volume in $1 \mathrm{~s} ; \mathrm{VC}$, vital capacity.

Table A2 Baseline values of the respective follow-up groups

\begin{tabular}{|c|c|c|c|c|c|c|}
\hline & $\mathbf{n}$ & Age (y) & $\begin{array}{l}\text { Gender ( } \% \\
\text { female) }\end{array}$ & $\begin{array}{l}\text { Pre-FEV }_{1}^{*} \\
\text { (ml) }\end{array}$ & $\begin{array}{l}\text { Pack-year } \\
\text { (No) }\end{array}$ & $\begin{array}{l}\text { Smoking status } \\
\text { (\% ever smokers) }\end{array}$ \\
\hline \multicolumn{7}{|l|}{ At risk subjects } \\
\hline Baseline group & 604 & 43.4 & 59.9 & 3058 & 9.1 & 32.0 \\
\hline Monitoring group & 384 & 42.9 & 57.6 & 3109 & 8.9 & \\
\hline Reassessed group (year 5) & 313 & 43.9 & 59.4 & 3065 & 8.7 & 32.6 \\
\hline \multicolumn{7}{|l|}{ Subjects without abnormalities } \\
\hline Baseline group & 551 & 42.9 & 50.3 & 3440 & 7.0 & 37.4 \\
\hline Reassessed group (year 5) & 151 & 42.9 & 50.3 & 3477 & 8.9 & 43.1 \\
\hline
\end{tabular}

*Pre-bronchodilator forced expiratory volume.

$\mathrm{FEV}_{1}$, forced expiratory volume in $1 \mathrm{~s}$. 